\title{
Unresponsive to Stimuli
}

National Cancer Institute

\section{Source}

National Cancer Institute. Unresponsive to Stimuli. NCI Thesaurus. Code C122529.

An individual whose level of consciousness is such that he is not responsive to any stimulus. 